\title{
Health Care Ethics
}

\section{Sahreen Malik Bhanji*}

The Aga Khan University School of Nursing and Midwifery, Pakistan

\section{Introduction}

In this rapidly changing world, healthcare professionals face multiple challenges encircling ethical dilemmas. There is often a conflict between the healthcare professionals and patients regarding the best choice. The nurse is often the person who acts as an advocate and resource to the patient. One of the best tools which healthcare professionals especially nurses rely upon in these challenging situations is the ethical decision making process. The four principles of healthcare ethics namely (Autonomy, Beneficence, non-maleficence, and justice) presented by (Beauchamp and Childress, 2001) [1] provide us a direction to estimate the significance of the ethical decision in clinical setting. It is important to note here that the application of these ethical principles may vary according to the situation. It also depends on the laws governing to the principle and the conditions applied.

In the paper to follow, I will discuss the implications of these four ethical principles in regard to the scenario in which a nurse is asked by the family members to withhold the information about the poor prognosis of the disease from a patient who is diagnosed with an inoperable tumor. The paper will also provide a compare and contrast of the application of these ethical principles in the given situation followed by the best possible solution.

\section{Critical Analysis of the Situation}

Looking at the scenario, the question that arises is whether the harm in not telling the patient about poor prognosis of the disease greater than the harm from telling the patient about the poor prognosis.

As part of the nursing curriculum, nurses are inculcated a habit of truth telling and honesty. These are considered as the fundamental principles of nursing. The ideology and core values of nursing include trustworthiness and honesty but are not limited to these two. However in the situation described above, the nurse is in a dilemma whether to hold the news of prognosis from the patient or not. In this situation, there is conflict between what is right and what is wrong. In terms of moral ethics, the nurse should speak the truth and convey the news to the patient. While on the other hand, the nurse has to respect the decision of the family of withholding the information which is thought to be in favor of the patient as revealing the truth might deteriorate patient's condition. Nevertheless, the consequences of such a decision to hold the news of poor prognosis could cause a delay in further treatment plan, and later on some paternalistic approach as directed by the family members in terms of care. Such a situation may continue for a longer period of time and may override the ethical principle of autonomy. Another angle to this situation is the breaking apart of the therapeutic relationship between the nurse and the patient that could occur as a result of withholding the information.

\section{Compare and Contrast of Ethical Principles in the Situation}

\section{Autonomy}

The principle of autonomy applies in terms of rights and obligations. It emphasizes on the rights of patients to take decisions about their medical treatment. According to Beauchamp and Childress (2001) [1] autonomy relates to being "free from controlling influences or personal limitations such as inadequate understanding" (p.56). The healthcare providers are obliged to be truthful (veracity) to their patients and to respect the choices that their patients make. This is supported by Edwards (2011) who believes that "the obligations to respect autonomy include the obligation to be truthful to the patient" (p.107). The patients have the right to decide for themselves in regard to the treatment plan, provided that they receive complete, accurate and comprehensive information. Relating this with the scenario above, the nurse who is asked by the family not to disclose the news of poor prognosis violates the ethical principle of autonomy by not giving the patient the complete information and therefore no choice to decide for herself the future treatment plans. Edwards (2011) believes that by keeping the necessary information from the person, the number of choices available to that person is reduced which inhibits her autonomy. Consequently, while hiding the news the nurse at some point in time in future may provide false reassurance to the patient or give the wrong information so as to fulfill the family's expectation of avoiding to tell the truth to the patient.

Another aspect of the situation i.e. hiding the prognosis from the patient and informing it to the family is in its self another ethical dilemma. In the given situation, this is to be noted that there is a collective decision made by the family for the patient but the patient herself is not the part of this decision. The question arises, to what extent is it right to share patient related information with the family when the patient is in a perfect state of receiving and processing the information. The answer to this question can be found in the American Nurses Association (2001) code of ethics for nurse's provision 2, which states that the nurse's primary commitment is to the patient. It can either be an individual, family, group, or community. Therefore the nurse's primary responsibility is the patient and not the family. While autonomy is taken in terms of rights and obligations, this takes us to the next two principles; the principles of beneficence and non-maleficence which are considered in terms of the consequences or outcome.

\section{Beneficence and Non-maleficence}

If the scenario is analyzed, and the family's decision of hiding the prognosis is taken into consideration, a question arises about the intentions of the family. However, if the intensions are good then this act takes us towards the ethical principles of beneficence and nonmaleficence. The ethical principle of beneficence requires healthcare professionals to treat their patients in a way that provides maximum benefit to that patient. While on the other hand, the principle of nonmaleficence assures the duty of healthcare staff to avoid causing any

*Corresponding author: Sahreen Malik Bhanji, Aga Khan University School of Nursing and Midwifery, Pakistan, E-mail: sahreen0707@gmail.com

Received April 06, 2013; Accepted April 29, 2013; Published May 04, 2013

Citation: Bhanji SM (2013) Health Care Ethics. J Clinic Res Bioeth 4: 142. doi:10.4172/2155-9627.1000142

Copyright: (c) 2013 Bhanji SM. This is an open-access article distributed under the terms of the Creative Commons Attribution License, which permits unrestricted use, distribution, and reproduction in any medium, provided the original author and source are credited. 
harm to the patient [2]. The principle of non-maleficence dates back to Florence Nightingale who strongly believed in doing no harm to the patient. This means that it is the responsibility of the healthcare professionals to protect their patients. This goes along with the ethical theory of utilitarianism which believes in the actions that provide the highest good for the maximum number of people. In healthcare ethics, utilitarianism supports the idea of maximum benefits and minimized costs and risks [4]. The two principles of beneficence and non- maleficence often go simultaneously hand in hand. However, they may override each other at times. In the given situation where the nurse is asked to keep away the news of poor prognosis, the decision to do so may be in favor of the patient and the intention of the family members to do so may be to protect the psychological wellbeing of the patient through beneficence. This act according to Edwards [5] outweighs the respect for autonomy in regard to obligations of non- maleficence. However, in doing so, the nurse may lose the trustworthy relationship built with the patient. In addition to the therapeutic relationship, if the diagnosis is accidentally revealed to the patient, she might end up to more serious complications like suicidal attempt or acts of self harm. Moreover, hiding the news may end up in mental and psychological trauma to the patient which could be more fatal than the disease itself. In this way, the principle of beneficence holds true but the probability of non-maleficence is high.

\section{Conflict between Autonomy and Beneficence}

The principle of autonomy often comes into conflict with the principle of beneficence. In this situation, intentionally or unintentionally, healthcare professionals use paternalistic approach while caring for their patients as they consider that approach as useful for their patient. Though the intervention seems useful for the patient, yet it breaches the autonomy of the patient by disrespecting the right of her decision in the treatment. It is important to note that while situations like these require healthcare professionals to critically analyze the risks and benefits associated with the choices that they make, in the process of choosing the best option, the entire situation along with its consequences should be taken into account, well discussed and planned so that the decision made should promote maximum beneficence and minimum or no harm with respect to autonomy.

\section{Justice}

The literal meaning of justice is equality and fairness. In healthcare industry, justice refers to equitable distribution of resources. Conn et al. mentions about different forms of justice such as distributive justice and the rights based justice. The rights based justice deals with respect to people's rights rather than the law. It is believed that and especially in healthcare industry that all individuals have equal rights in terms of seeking healthcare and to participate in their plan of care. Taking into account the scenario discussed above, the nurse violates patient's right to receive full information regarding her disease prognosis and above all the information is being transferred to the family without her consensus. Moreover, another ethical dilemma is that since there is no mention about any personal limitations or incapability because of which she would not be able to process the information then the act of not disclosing the information or truth to her is incorrect. In this situation, patient's rights are being disrespected and disregarded in the presence of laws that guide towards holding back the news of poor prognosis from the patient. This is also supported by the American Nurses Association (2001) [3] code of ethics for nurse's provision 3, which states that nurse must promote and advocate for and make an effort to protect the health safety and rights of the patient. In contrast to this statement, the nurse in this situation clearly violates the right of the patient to know about the poor prognosis.

\section{Analyzing Context}

The situation described here has no perfect answer. In this situation we cannot come to a perfect conclusion, rather we can analyze the situation and use the ethical decision making process and apply the best possible principle. It is difficult to come to a conclusion due to certain reasons. Firstly, the description of the situation is very brief. One cannot analyze or evaluate all the aspects of the situation with this brief explanation. Secondly, proper assessment of patient's own support systems and coping mechanisms need to be assessed before coming to a conclusion. Thus making a judgment as to which ethical principle applies best in the given situation would be difficult. The Nurse could wait, assess the patient for the degree of acceptance and let the physician involve or take over. It is equally important to access the family condition and ties. Moreover the competency and threshold of the patient needs to be accessed before coming to a conclusion. However analyzing the situation with all its intrinsic and extrinsic factors, a decision can be made considering the best possible outcome in favor of the direct recipient of care (patient). Moreover, following pragmatism, a suitable and most practical decision should be made keeping in mind the consequences that may occur. Along with all these factors, Edwards believes that "all actions by healthcare professionals have a moral dimension to them" (p.108) therefore in any such situation where an ethical decision has to be made, it has to be kept in mind that these situations are not only medical but has a moral dimension to it as well which if not considered, the chances of error or wrong decision may go high.

\section{Conclusion}

To sum up, there seems no perfect answer to an ethical dilemma. The paper has discussed the application of the ethical principles in the given situation. It is hard to justify the use of one principle over another. Yet the ethical decision making process provides a guide to take a step ahead and apply the best possible principle. However, it may not be the perfect choice but it may result in maximum beneficence and minimum harm which could be avoided. The framework that guides nursing practice for example the America Nurses Association code of ethics and the patient's bill of rights should also be taken into consideration while deciding for the best choice in situations which give rise to an ethical dilemma. Nevertheless, in any such situation, pros and cons and risks and benefits should be weighed against to get to the best possible solution which would be in favor of the patient.

\section{References}

1. Beauchamp TL, Childress JF (2001) Principles of biomedical ethics. (5thedn) New York: a) Oxford University Press.

2. Conn J, Gillam L, Conway G S (2005) Revealing the diagnosis of androgen insensitivity syndrome in adulthood. BMJ, 331: 628-630.

3. American Nurses Association. (2001) Code of ethics for nurses with interpretive statements. Washington, DC: American Nurses Association.

4. Mack $P$ (2004) Utilitarian Ethics in Healthcare. International Journal of The Computer, the Internet and Management, 12: 63-72.

5. Edwards SD (2011) Nursing ethics: A principle-based approach. 